Van de Walle, S. (2009). 'When is a service an essential public service?'. Annals of Public and Cooperative Economics, 80(4): 521-545.

WHEN IS A SERVICE AN ESSENTIAL PUBLIC SERVICE?

Steven Van de Walle

Department of Public Administration

Faculty of Social Sciences

Erasmus University Rotterdam

The Netherlands

vandewalle@fsw.eur.nl

\footnotetext{
${ }^{1}$ Research for this article was part funded through my ESRC Public Service Programme Fellowship on "Public attitudes towards services of general interest in comparative perspective" (RES 153-27-0004). Earlier version of this article have been presented at the Political Studies Association Annual Conference in Swansea (1-3 April) and at the Public Values and Public Interest workshop in Copenhagen (28-31 May 2008).
} 
WHEN IS A SERVICE AN ESSENTIAL PUBLIC SERVICE?

\begin{abstract}
Citizens consider certain public (and private) services as essential services and therefore to be shielded from the full extent of market forces. Little is known about why some services are considered essential public services while other sometimes very similar services are not. In this article, we analyse public opinion using Eurobarometer data to test models exploring what factors determine whether citizens in $15 \mathrm{EU}$ countries consider certain services as essential services and therefore to be provided to all. Despite the variety in public opinion, political orientations and geographic factors do little to explain why citizens have different opinions about the provision of public services. The article ends by outlining a research agenda for the further analysis of this underexplored research topic
\end{abstract}

Keywords: Services of General Interest, public service values, liberalisation, essential public services, political attitudes 


\section{WHEN IS A SERVICE AN ESSENTIAL PUBLIC SERVICE?}

The importance of many, if not most, public (and private) service stretches beyond the mere delivery of a service or product to an individual customer. Presence or absence of these services does not only have an effect on the individual customer, but also on the wider society. When a railway station or post office in a rural area closes, this has important implications for the identity and fabric of this area. When a family is disconnected from the electricity or water mains, this has value implications that go beyond this individual case. At the European level, 'services of general interest' (SGI) is used as a term to refer to public and private services that have a 'general interest' dimension (Commission of the European Communities 2001). Generally included in this category are such services such as utilities, public transport, mail services etc. It is recognised that these services cannot be left entirely to the market, because of a desire to protect certain values (De Bruijn and Dicke 2006). A core value is the universality of these services. This value reflects the desire to guarantee a certain level of access to these services to all. Some of these services are thus considered as 'essential' services, the lack of which for an individual or a group of individuals is to be considered as problematic and to be remedied by some type of (government?) intervention. In this article, we test a series of models exploring what factors determine why citizens in $15 \mathrm{EU}$ countries consider certain (public) services as essential services and therefore to be provided to all.

In discussions and policy about access to public services, two dimensions are typically mentioned (Van de Walle 2008). A geographical dimension deals with access to services of general interest in all geographical areas. It especially applies to rural, remote, or sparsely populated areas. Delivering services in these areas comes at a cost, and it is not always desirable to have the direct users of these services in these areas bear all the extra costs. A trade-off therefore needs to be made between delivering the same level of services in all geographical areas at the same cost, delivering differentiated services at differential cost, or even not providing the service at all. Typical examples include having post offices in remote areas, the frequency of delivering mail in these areas, or the access and cost of linking houses to water mains or fast internet. The social dimension deals with the fact that accessing services under pure market conditions may be too expensive for some. Certain guarantees may then be required to avoid families being cut off from electricity or water. Recent initiatives in some countries also include access to basic internet services at home for job seekers, or special arrangements for using television and telephone for the elderly.

There is little agreement on what is implied in the 'publicness' of public services, or on how the 'general' or 'public' interest is to be expressed in the regulation and reform of public 
services. Within the EU countries, we see a myriad of initiatives, and different national systems appear to have their own approaches (Prosser 2000). Some services are clearly considered as more essential than others, as is reflected by very similar universal service obligations for utilities such as water and electricity across countries. When certain services are qualified as essential, a rationale for state intervention emerges. The way how the performance of these services will be assessed will change (Van de Walle 2008). It is therefore not a trivial matter.

In this article we explore the effect of two potential explanations for why citizens consider certain services as essential services, and others not. One is the role of political ideology, whereby it could be hypothesised that a more leftish political opinion is related to a stronger likelihood of defining certain services as 'essential' services, and therefore to be provided to all, regardless of whether there is a market-economic logic for doing so. The other explanation will look at geography. Much of the debate on the liberalisation of public services has focused on geographical aspects of delivery, and it is likely that inhabitants of rural or remote areas will have a different opinion of essential services than will inhabitants of urban areas. Those who live in rural areas will probably be more inclined to adopt a view that is broader than a market-economic one, because this best suits their interest of keeping the cost of services down and access easy.

We first describe different methods to establish which services are considered as essential services within a certain context. We then introduce our data, and proceed with building an explanatory model for 15 EU countries, and develop a number of explanations for the findings. We end by outlining a research agenda for the further analysis of this underexplored research topic.

\section{Which public services are 'essential'?}

'Essential' public services is an undefined and changing concept (Van de Walle 2008). There is no fixed definition. Discovering which services are considered essential has therefore to be done in an indirect way, by looking at practices, behaviours, documents, and opinions. There are several ways to infer which services are seen by policy makers and societies as essential services.

A first possibility would be to look at universal service obligations (USOs), and the concerns and trends expressed by these USOs. When a service is subjected to a lengthy series of such obligations, this reflects certain concerns about the universality and continuity of this service. Changes over time in these USOs or international cross-sectional differences then show how 
conceptions of what is an 'essential service' may vary across time and space. Across Europe, there is a considerable degree of convergence between those USOs in specific sectors, which suggests a certain consensus about which services are 'essential' (public) services (Cremer, Gasmi et al. 2001).

An alternative option is to analyse political and policy discourse and documents, and to interpret the concerns reflected in discourses and documents. One source of such information is the European policy on services of general interest, which gives us some hints as to what kinds of services are considered to be different from mere disposable market services (Clifton, Comin et al. 2003; Prosser 2005). Other sources may include political speeches, party programmes, protest movements, or policy papers.

A third option is to analyse legal systems and legal precedents. A historical analysis of concepts such as 'service public' as it is for instance used in France, or of the concept of 'common callings' in common law shows how concerns about service continuity and nondiscrimination have changed over time (Van de Walle 2008). Additionally, we may want to look at evolutions in European case law on services of general interest and liberalisation to analyse how the thinking about essential (public) services is changing (Prosser 2005).

Finally, and this is the approach we will take in this article, one can analyse public opinion. Using this approach, one can infer that a society considers a certain service as 'essential' when a substantial proportion of its population considers this service as essential. In a French survey on rural services, postal services, schools, and health care came in on top of a list of services mentioned as of general interest, and therefore to be provided nearby (Ministère de l'Intérieur et de l'Aménagement du Territoire (France) 2005). We find some older evidence in a 1997 Eurobarometer opinion survey (INRA 1997), where a question was included on essential services or services that ought to be guaranteed to everyone. Respondents in 15 countries were asked whether they considered certain public services as essential public services (see also further down in this article). The results showed that services such as water and electricity distribution and garbage collection were most frequently considered as essential services.

Despite this being a very crude way of measuring whether certain public services are considered essential services, the results give us a first indication. Opinion surveys may not be the best method for establishing whether a public service is considered as an essential public service. Freedland has suggested that in a consumerist public sector culture this may lead to citizens considering all services as essential (Freedland 1998: 24-25). There may also be arguments for looking at citizens' behaviours vis-à-vis public services rather than their 
attitudes. One suggestion could be to look at citizens' reactions to post office closures or public transport strikes.

In the following sections, we will use public opinion data on attitudes towards certain public services to analyse what services citizens consider as essential services, and will make a start with analysing determinants of such opinions and differences in opinions.

\section{Data}

The European Commission's Eurobarometer surveys are organised to support EU decision making. For this reason, there have been several Eurobarometer surveys focusing on public services and services of general interest, and related issues of price, choice and access. Typically, these surveys have focused on services such as mobile telephony, rail transport, postal services and various utilities. Only one of these surveys has explicitly mapped which services citizens consider as essential services. The historical Eurobarometer 47.0 dataset (1997) is the only one directly probing for citizens' opinions on essential (public) services in a series of countries. Similar material exists for some individual countries, notably Belgium (Van de Walle, Van Roosbroek et al. 2008) and France (Ministère de l'Intérieur et de l'Aménagement du Territoire (France) 2005), but obviously this material does not allow making international comparisons due to different research designs and wording of questions. For international comparative purposes, therefore, this 1997 dataset remains a very valuable source. The analysis in this article builds on an earlier one in which we only analysed the Belgian data (Van de Walle 2006). The survey has been organised in the (then) $15 \mathrm{EU}$ member states and around 1,000 people were interviewed in each country ${ }^{2}$. The total dataset has 16,362 respondents.

\section{Analysis}

As dependent variable, we use question 38 from Eurobarometer 47.0: 'Some people think that everyone should have the right to certain services even if they do not have the means to pay for them. Which of the following services should, in your opinion, be guaranteed to everyone?'. Respondents were provided with a list of services and could select as many services as they liked. The answers have subsequently been noted as 'mentioned' or 'not mentioned'. The overall results for the EU15 countries are in figure 1.

\footnotetext{
${ }^{2}$ The sample for Germany was twice as large to allow for East-West comparisons, and the British sample is larger to allow for separate analysis of Northern Ireland. We will therefore apply weights where appropriate.
} 
Figure 1: Services that should be guaranteed to everyone, 1997, EU15

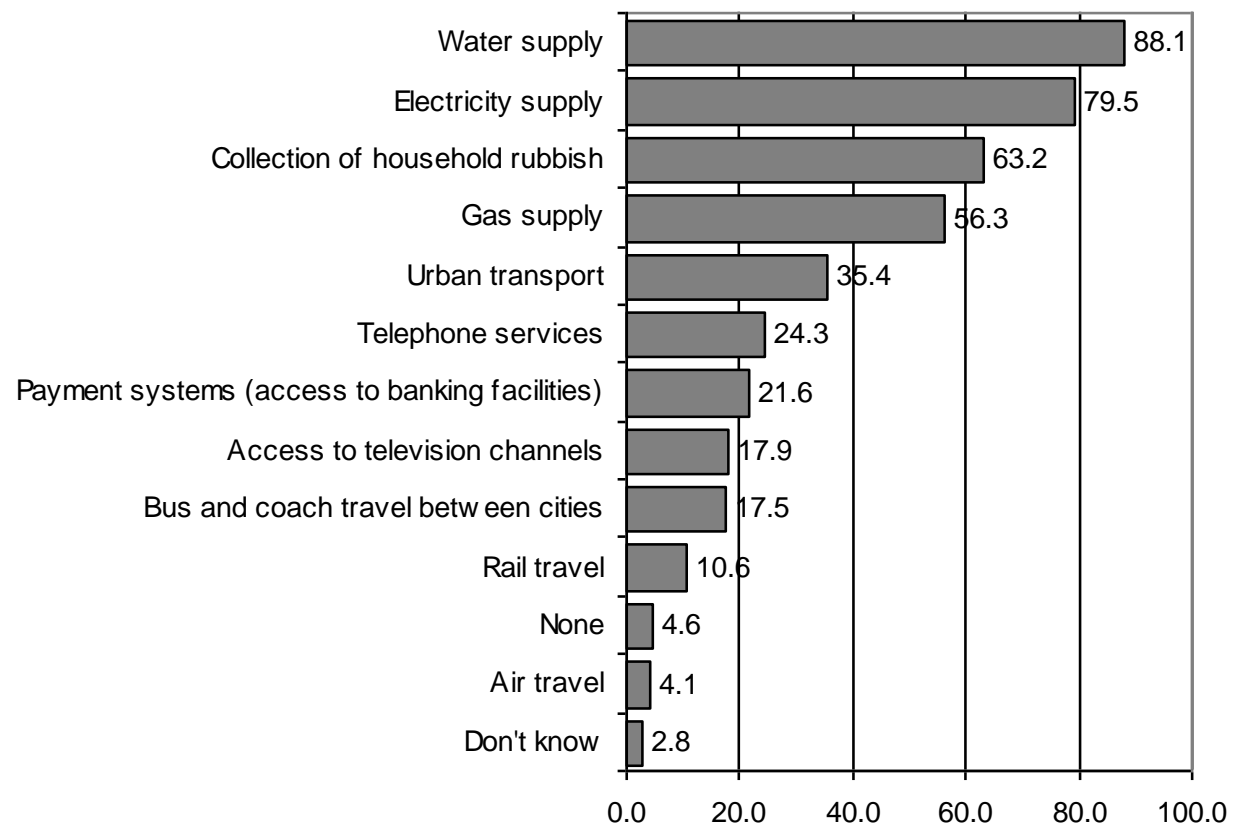

Source: Eurobarometer 47.0, ZA2935, Jan.-Feb. 1997. Figure shows \% of respondents who mentioned the services. Results for entire EU15, weighted by countries' population size.

A large majority of respondents considers services such as electricity and water supply as essential services that should be guaranteed to everyone, even to those who don't have the means to pay for them. Rubbish collection and gas supply are also mentioned quite often. The number of respondents considering a service as essential starts to decline rapidly after that: about a third thinks urban transport should be guaranteed to everyone, a quarter thinks the same for telephone services, and about a fifth thinks access to television, coach and bus travel between cities and banking facilities should be guaranteed to all. Just over 10 per cent considers rail travel an essential service. A very small group thinks that air travel should be guaranteed to everyone, and an equally small group thinks that no services should be guaranteed when means to pay for them are not available.

There are a number of important differences between countries (not in the figure). Rubbish collection should be guaranteed to everyone according to 79 per cent of the Dutch and 72 per cent of the Danes, but only 45.7 per cent of Greeks and 52 per cent of Italians agree. Banking facilities are mentioned by 40.2 per cent of the Fins, but by less than 10 per cent of the Italians, Spanish and Portuguese. Urban transport is not considered essential by many Danes, while 40.7 per cent of the French think it should be guaranteed to everyone. More than a third of the Germans think that access to TV channels should be guaranteed to all, while this number is just a bit over 10 per cent for the Danes, French, British and Luxemburgish. We see similar major differences for telephone services: 37.8 and 34.6 per cent of respectively the 
Greeks and the Belgians consider them essential, while this holds for just 13.3 per cent of the Danes.

A number of these differences are due to country-level differences in organisation of these services. A good example is gas supply, where 83.5 per cent of the Dutch consider this an essential service, compared to less than a quarter of the Greeks and the Fins. A (semi-)public infrastructure to supply individual houses with gas is more common in some countries than in others. Another example is bus and coach travel between cities, which is quite common in some countries, and quasi non-existent in other; or rail travel, which may take a more prominent place in citizens' transportation options in some countries than it does in others. A related factor is the extent to which citizens of a certain country may have grown accustomed to the provision of certain services, while the same services may be a rather new or a marginal phenomenon in other countries.

A further comparison of country-level differences suggests there may be an effect of population density and degree of urbanisation on the responses. The presence or absence of certain services such as urban transport or rubbish collection may have a different impact on citizens depending on whether they live in an urban or a rural setting. Finally, national political and administrative cultures may have an effect on opinions. In Belgium, for instance, the percentage of respondents identifying a certain service as essential is generally quite high for many services, while this percentage is often quite low in Denmark.

Obviously, because this data is historical, some changes may have occurred over time. The most important ones being the proliferation of the internet (not included in this survey), and the impact of this change on the access to banking facilities or television.

\section{What determines whether a service is seen as essential?}

In the previous section, we have shown that there are a number of differences between countries, and that within countries opinions tend to vary considerably. In this section, therefore, we will develop a model for describing and explaining within-country differences. As we have mentioned, the actual provision and organisation of services differs considerably between countries. This makes certain services less amenable to analysis. Examples include gas supply, inter-city bus travel and rail travel. Because of the low frequency, air travel will also be dropped from the analysis. Water and electricity supply are mentioned as essential services by a large number of respondents. The lack of variation in the answers makes these services less suitable for analysis. This leaves us with five services:

- Collection of household rubbish 
- Access to television channels

- Urban transport

- Payment systems - access to banking facilities

- Telephone services

We are interested in two main determinants of attitudes towards the provision of (public) services, as already mentioned in the previous sections: 1) how do political opinions influence these attitudes?; and 2) how does the degree of urbanisation of one's place of residence influence opinions on the provision of public services?

In this Eurobarometer survey, only a limited number of variables are available. For the political dimension we use the following variable:

'In political matters, people talk of "the left" and "the right". How would you place your views on this scale?' (where 1 is left, and 10 is right)

For the analysis, it has been recoded into three categories: left, centre, and right. While this is an essential variable for our model, it is also one where many respondents prefer not to answer. The overall combined don't know/refusal/missing rate amounts to 16.4 per cent, ranging from a mere 6.9 per cent in Sweden, to 26.4 per cent in Italy. This may have implications for our models. One implication is that it results in a lower number of cases. If we can assume that non-response is evenly spread over the categories (left, centre, right), this has few consequences for the results. Unfortunately, we know that non-response, especially on this kind of variable, may be related to certain social and political attitudes (Loosveldt and Carton 2002). The exclusion of these cases may therefore have an (undefined) effect on the results.

Where political self-identification has an effect on the dependent variable, many, but not all, bivariate findings point in the same direction: identifying certain public services as essential is related to one's political self-identification. Having leftish political views is related to a higher probability of mentioning that a certain service should be guaranteed to everyone. However, while significant (Chi square test), the differences are generally very small.

Table 1: Bivariate relations between political self-identification and defining services as essential

\begin{tabular}{|c|c|c|c|c|c|c|c|c|c|c|c|c|c|c|c|}
\hline & $F R$ & $B E$ & $N L$ & $D E$ & $I T$ & $L U$ & $D K$ & $I E$ & $U K$ & $G R$ & $E S$ & $P T$ & FI & $S E$ & $A T$ \\
\hline Water & $\mathrm{L}$ & & & & & & & & & & & & & & $\mathrm{C}$ \\
\hline Gas & $\mathrm{L}$ & $\mathrm{L}$ & & & & $\mathrm{L}$ & & & & $\mathrm{C}$ & & & & & \\
\hline Electricity & & & & & & & & $\mathrm{R}$ & & & $\mathrm{C}$ & & $\mathrm{L}$ & & \\
\hline Telephone & & $\mathrm{L}$ & $\mathrm{L}$ & $\mathrm{L}$ & & & & $\mathrm{R}$ & $\mathrm{C}$ & & & $\mathrm{L}$ & & & \\
\hline & $\mathrm{L}$ & & & $\mathrm{L}$ & & & & & & & & & $\mathrm{L}$ & & \\
\hline Rubbish collection & & $\mathrm{R}$ & $\mathrm{L}$ & & & & $\mathrm{L}$ & & & & & & & & \\
\hline Rail & $\mathrm{L}$ & & $\mathrm{L}$ & & & $\mathrm{L}$ & & & $\mathrm{L}$ & & & & & & \\
\hline
\end{tabular}




\begin{tabular}{l|lllllll}
\hline IC bus \& coach & & & & L & & & \\
Urban transport & L & L & L & L & & C & L \\
Payment systems & L & L & L & & L & L & \\
\hline
\end{tabular}

Legend: Letters indicate category where service is most frequently mentioned as essential. L=left; $\mathrm{R}=$ right; $\mathrm{C}=$ centre; only includes significant relations.

The relations are quite consequent in some countries, and less so in others. In countries such as France, the Netherlands, Germany or Luxemburg, a leftish political orientation is related to labelling a series of services as essential. In other countries, the effects are less straightforward or even absent.

The second key variable is the degree of urbanization of one's locality. Eurobarometer is using a country-specific measure for the size of one's locality ${ }^{3}$. It has been recoded into a new variable with three values: $1 /$ rural; $2 /$ mixed; 3/urban. Table 2 again shows the bivariate findings.

\footnotetext{
${ }^{3}$ This recoding is not without risk because different definitions have been used in different countries. Sometimes, these are based on a description of the type of locality, in other cases on population numbers. The latter always have to be interpreted relatively to size of the country. Therefore, the new variable has only 3 categories: rural areas/small villages, large cities, and a middle category
} 
Table 2: Bivariate relations between urbanization of respondent's locality and defining services as essential

\begin{tabular}{|c|c|c|c|c|c|c|c|c|c|c|c|c|c|c|c|}
\hline & $F R$ & $B E$ & $N L$ & $D E$ & $I T$ & $L U$ & $D K$ & $I E$ & $U K$ & $G R$ & $E S$ & $P T$ & $F I$ & $S E$ & $A T$ \\
\hline Water & & $\mathrm{C}$ & & $\mathrm{R}$ & $\mathrm{R}$ & & & & $\mathrm{C}$ & $\mathrm{CR}$ & & & $\mathrm{C}$ & & $\mathrm{M}$ \\
\hline Gas & $\mathrm{C}$ & $\mathrm{RC}$ & & & & & $\mathrm{C}$ & $\mathrm{C}$ & $\mathrm{C}$ & & $\mathrm{C}$ & & M & $\mathrm{C}$ & $\mathrm{CM}$ \\
\hline Electricity & & & & $\mathrm{RC}$ & $\mathrm{R}$ & & $\mathrm{C}$ & $\mathrm{R}$ & $\mathrm{C}$ & $\mathrm{R}$ & $\mathrm{C}$ & & & & RM \\
\hline Telephone & $\mathrm{R}$ & & & & & & & $\mathrm{R}$ & $\mathrm{C}$ & $\mathrm{R}$ & & & & & M \\
\hline TV & & $\mathrm{C}$ & & & & & & M & & & & & & & M \\
\hline Rubbish collection & $\mathrm{C}$ & $\mathrm{CM}$ & & & & & & $\mathrm{CM}$ & & $\mathrm{C}$ & $\mathrm{C}$ & $\mathrm{CM}$ & M & & M \\
\hline Rail & & $\mathrm{CM}$ & & & & $\mathrm{RM}$ & & & & & & M & & & RM \\
\hline IC bus coach & & & M & & & $\mathrm{R}$ & & $\mathrm{RM}$ & MC & & $\mathrm{R}$ & & & $\mathrm{RM}$ & \\
\hline Urban transport & $\mathrm{C}$ & $\begin{array}{l}\mathrm{C} \\
\mathrm{C}\end{array}$ & $\mathrm{C}$ & $\mathrm{C}$ & $\mathrm{C}$ & RM & $\begin{array}{l}\mathrm{C} \\
\mathrm{C}\end{array}$ & RM & & $\begin{array}{l}\mathrm{C} \\
\mathrm{MC}\end{array}$ & $\mathrm{C}$ & $M$ & M & $\mathrm{C}$ & $M$ \\
\hline
\end{tabular}

Legend: Letters indicate category where service is most frequently mentioned as essential. $\mathrm{C}=$ city; $\mathrm{R}=$ rural; $\mathrm{M}=$ mixed rural/urban; $\mathrm{MC}=$ mixed and city; $\mathrm{MR}=$ mixed and rural; $\mathrm{RC}$-rural and city; only includes significant relations.

Here, a very mixed picture emerges. However, one observation is striking: living in a city tends to be related to mentioning certain services as essential, more so than living in a rural area. This appears to be counterintuitive. Public policy has tended to focus on public service provision in rural and remote areas. These findings now suggest that inhabitants of rural areas are less concerned with the availability of and access to these services. There are of course a number of obvious explanations for certain findings. One concerns the variable on urban transport. Precisely because of the way how this question was asked, rural populations may consider it as less essential. Had the question been phrased as 'public transport', answers may have been different. Another explanation could be that inhabitants of urbanised areas have grown accustomed to certain services, less than is the case for inhabitants of rural areas.

In what follows, we will further test the effect of political self-identification and urbanization on attitudes towards essential services. To this end, we will build a number of models for the five services mentioned above with these two variables and a number of control variables. The control variables are: sex, age, level of education, income, and opinion leadership.

- Sex is simply coded as $0=$ female $/ 1=$ male;

- The age variable lists the age in years;

- Education has been recorded as the age when the respondent left full time education. Respondents still studying have been assigned to the school-leaving category corresponding to their age;

- The income variable is a transformation of country-specific income groups, and puts the respondents in income quartiles. Given the sensitivity of this income question, there is 26.1 per cent refusal and no answer rate. Because this would lead to a massive reduction of the number of valid cases in the model, we have randomly assigned the 
non-responding respondents to the two middle income categories, as to minimize impact;

- Finally, we use an opinion leadership index as a measure of political sophistication. This index is composed of two variables: the frequency of discussing political matters with friends, and the frequency of persuading friends of one's opinion. This index has also been recoded, and can take four values: low, medium low, medium high, and high $^{4}$.

\section{Findings}

\section{International findings}

We ran five types of binary logistic regressions, one for each of the five services. This model was tested both for the entire dataset and for each of the individual countries separately, making a total of 80 regressions. The results were disappointing. One out of seven models did not fit at all. Of the other models, $\mathrm{R}$ squares were generally low - only very occasionally higher than .10 - and there were few overall trends. Reporting all the findings in detail would lead us too far, so we only report some observations and trends.

In the majority of the models, political self-identification had no significant effect on identifying certain services as 'essential'. Where it did have an effect, however, it was, with just two exceptions, similar: respondents identifying themselves as being politically on the left are more likely to think that certain public services ought to be guaranteed to everyone. This appears to be especially the case for public transport, and to some extent for payment systems. This finding, while very weak, is line with our expectations. With some minor exceptions, political self-identification is not relevant in the models for telephony, rubbish collection, or access to TV channels.

The effects of urbanization are counterintuitive but largely in line with our earlier analysis of the Belgian Eurobarometer data (Van de Walle 2006): Whether one lives in a rural, urban or mixed urban/rural area does not generally have an effect (in a multivariate model, that is) on opinions about the essentiality of certain public services. Where there is an effect, however, the dominant (but by no means strong) effect is that inhabitants of rural areas are less likely to consider certain services as essential. The trend is quite clear for rubbish collection, where those living in a rural area tend not to consider this service as essential. Alternatively, inhabitants of cities tend to consider rubbish collection as essential. Again, however, this variable is not significant in all countries. For services such as access to TV channels or telephony, urbanization is largely irrelevant. Urbanisation does have an effect on attitudes

\footnotetext{
${ }^{4}$ Not included in the models for Ireland, Portugal, Spain, and Germany
} 
towards urban public transport, which is considered to be less essential to inhabitants of rural areas. This is not surprising given the question wording with a focus on urban transport.

For urban transport, there frequently is an effect of education: A higher education is related to defining this service as a service that needs to be guaranteed to all. Age has an effect on attitudes towards payment systems, telephony, and rubbish collection. Younger respondents tend to see rubbish collection and payment systems as essential services, while telephones are more likely to be seen as essential by older respondents. Finally, male respondents are more inclined to consider access to TV channels an essential service. However, we only find an effect in five countries.

Summarising, the findings are overall quite disappointing: the models are very weak, and the consistency across countries is limited. However, the analysis suggests some avenues for further research. The age effect suggests that personal circumstances and experiences may play an important role in defining certain services as essential (e.g. telephones for older people). The same may hold for the level of urbanisation, whereby it may be easier to imagine the absence of certain services within a different geographical context. The findings about the effect of political self-identification suggest that it may be necessary to distinguish between services that feature prominently in certain ideologies or party programmes, and those that don't. Public transport is a good example.

\section{Findings - United Kingdom}

In this section we look at the findings for the United Kingdom in somewhat more detail. We ran the same regression model on all 11 services. Findings are in table 1. Overall, R squares are relatively low, ranging from .024 for rubbish collection to .096 for air travel (where there actually isn't much variation anyway - so it will not be discussed). The models for electricity supply and rail travel did not fit. The findings are really quite mixed, but it is reassuring that where effects have been found, the direction of the effect is generally the same, with one exception (sex). Below, we briefly discuss the findings for each of the individual services. 
Table 3: Binary logistic regressions - should these services be guaranteed to everyone (1=mentioned/0=not mentioned), United Kingdom

\begin{tabular}{|c|c|c|c|c|c|c|c|c|c|}
\hline & $\begin{array}{l}\text { water } \\
\text { supply }\end{array}$ & $\begin{array}{c}\text { gas } \\
\text { supply }\end{array}$ & telephone & $\begin{array}{l}\text { acc. TV } \\
\text { channels }\end{array}$ & $\begin{array}{l}\text { rubbish } \\
\text { coll. }\end{array}$ & air travel & $\begin{array}{l}\text { IC bus \& } \\
\text { coach }\end{array}$ & $\begin{array}{l}\text { urban } \\
\text { trans. }\end{array}$ & $\begin{array}{l}\text { payment } \\
\text { syst. }\end{array}$ \\
\hline Sex $(0=$ female $/ 1=-$ male $)$ & .451 & -.047 & $-.304^{*}$ & $.667^{\star *}$ & $.310^{*}$ & -.107 & -.186 & .151 & -.215 \\
\hline Age (years) & $-.018^{* *}$ & .002 & .004 & $-.014^{*}$ & $-.008^{*}$ & -.009 & .000 & .002 & $-.022^{* * *}$ \\
\hline Age left schooling (9 categ.) & -.053 & -.024 & $-.117^{\star \star}$ & $-.154^{\star \star}$ & .011 & $-.365^{\star}$ & $-.113^{\star *}$ & .037 & .015 \\
\hline Income $(\text { low })^{a}$ & .206 & -.068 & .406 & .536 & .172 & 1.103 & $.700^{\star}$ & -.207 & -.288 \\
\hline Income (medium low) ${ }^{a}$ & -.273 & -.084 & .161 & .510 & .111 & 1.036 & .498 & -.308 & $-.556^{*}$ \\
\hline Income (medium high) ${ }^{\mathrm{a}}$ & -.396 & -.195 & .364 & .466 & .232 & 1.018 & $.658^{*}$ & .090 & -.313 \\
\hline Opinion leadersh. (low) ${ }^{\mathrm{b}}$ & -.601 & -.485 & -.446 & -.011 & -.311 & -.778 & -.504 & $-.532^{*}$ & $-.627^{*}$ \\
\hline Opinion leadersh. (medium low) ${ }^{\mathrm{b}}$ & -.235 & $-.496^{\star}$ & -.357 & -.061 & -.071 & -.875 & -.406 & -.455 & $-.524^{*}$ \\
\hline Opinion leadersh. (medium high) ${ }^{\mathrm{b}}$ & -.416 & -.345 & -.331 & -.182 & .012 & -1.144 & -.311 & -.322 & -.493 \\
\hline Political views (left) ${ }^{c}$ & -.091 & -.042 & -.070 & -.014 & -.148 & $-1.258^{*}$ & .164 & .060 & .164 \\
\hline Political views (centre) ${ }^{c}$ & -.380 & .168 & .094 & -.329 & -.271 & -.307 & .144 & -.228 & .063 \\
\hline Location (rural) $^{\mathrm{d}}$ & $-.788^{\star \star}$ & $-.909^{\star \star *}$ & $-.535^{\star}$ & -.518 & -.241 & -.444 & $-1.028^{\star \star \star}$ & -.194 & .001 \\
\hline Location (mixed urban rural) $^{d}$ & -.116 & $-.351^{*}$ & -.321 & -.178 & -.106 & -.657 & -.021 & -.229 & -.232 \\
\hline Nagelkerke $\mathrm{R}^{2}$ & .060 & .050 & .051 & .067 & .024 & .096 & .059 & .034 & .060 \\
\hline $\mathrm{N}$ & 1,466 & 1,466 & 1,466 & 1,466 & 1,466 & 1,466 & 1,466 & 1,466 & 1,466 \\
\hline
\end{tabular}

Source: Eurobarometer 47.0. Models for UK - weight-adjusted for population-size of GB and N. Ireland. *p<0.1, **p<0.05, ***p<0.001. Reference categories are ${ }^{a}$ income (high), ${ }^{b}$ opinion leadership (high), ${ }^{c}$ political views (right), and ${ }^{d}$ city. Models for electricity supply and rail travel do not fit and have not been included in the table. 
Water supply: Older people are less inclined to see water supply as a service that should be guaranteed to everyone, even to people who cannot pay for it, while 95 per cent of young respondents $(<25)$ see this as a service that needs to be guaranteed to everyone. In rural areas, 15.7 per cent of respondents do not consider water supply an essential service, while this percentage drops to 5.7 per cent in cities and heavily urbanized areas.

Gas supply: The main effect in the gas supply model is, not surprisingly, urbanisation, where the majority of respondents in rural areas do not consider gas supply as a service that should be guaranteed to everyone, as compared to one third of the urban population thinking so. There also is an effect of opinion leadership, which was mainly used as a control variable.

Telephone services: One quarter of the urban respondents consider telephone services essential, as opposed to just 17.3 per cent of the rural population. Being lower educated and female is also associated with considering telephone services as essential services.

Access to TV channels: Young age $(<25)$, a lower education, and being male all contribute to defining access to TV channels as an essential service. Of the female respondents, 9.2 per cent mention TV as essential, and this number rises to 17.9 per cent for the male population. The differences due to education are quite strong in that TV is considered essential by 17.1 per cent of those who left education at 14 or earlier, while this percentage is considerably less than half for those who left full time education aged 21 or older.

Rubbish collection: Male respondents are more likely than females to see rubbish collection as an essential service. There also is an age effect, but the difference appears to be mainly due to the older respondents $(>65)$, who are considerably less inclined to mention rubbish collection as an essential service

Intercity bus and coach travel: a lower education and a lower income both lead to mentioning buses and coaches between cities as essential services. In the highest income groups, just 10.7 per cent of respondents mention intercity buses as essential, while this percentage almost doubles in the lowest income quartile. Location is also very important: just 8 per cent of the rural population mentions buses as essential, while this is 18.9 per cent for inhabitants of cities.

We find just one effect in the model for urban transport. Respondents scoring high on the opinion leadership index (i.e. discussing with and influencing friends about politics and current affairs) tend to identify urban transport more often as essential

Finally, payment systems or banking facilities are considered essential services by over 30 per cent of respondents under 35 . This percentage drops gradually by age to just half that for respondents over 65. Being an opinion leader leads to payment facilities being mentioned more often as an essential service. Finally, medium-low income groups are less likely to consider payment facilities as essential. 


\section{Challenges}

This article did not lead to the desired results. Rather than finding the anticipated results, or even contrary relations that would have required rejecting the initial hypotheses, the overall findings were generally weak or even absent. This is obviously a disappointing find for a researcher, but it is more common than what most published research suggests (Lehrer, Leschke et al. 2007). On the other hand, it creates a need to reconsider hypotheses and to rethink data, models, and theories. In this section, we will therefore deal with a number of problems in current data and conceptualizations, and suggest a number of avenues for further research on essential services.

\section{Measuring essentiality}

The indicator used in this article was 'Some people think that everyone should have the right to certain services even if they do not have the means to pay for them. Which of the following services should, in your opinion, be guaranteed to everyone?'. This question touches on one specific element of essential public services only, and may therefore be considered incomplete. The absence of other questions measuring different aspects of public service delivery may have reflected on the answers to this question, in that respondents' answers may not only have been inspired by the 'ability to pay' consideration, but also by other elements. In other words, there are reasons to assume that the formulation of the question cannot be taken at face value, because it may have invited opinions related to other aspects of essential services.

On the other hand, the findings may in fact say very little about attitudes towards essential service delivery, because of the prominent position of the ability to pay issue in this question. This may have distracted attention from essential service considerations to issues of economic inequalities, consumer behaviour, and the acceptability of state intervention.

Further exploration of attitudes towards essential services will require the development of a good scale consisting of more than just this single item. Such a scale would need to include a number of dimensions of essential service delivery, such as:

- territorial differentiation in price, quality and availability

- socio-economic differentiation in price, quality and availability

- differentiation in delivery channels and options.

Such a scale would present us with a 'fuller' measure of essentiality, and would allow us to distinguish between different dimensions of essentiality.

As mentioned in the introduction, there are also other ways to infer which services are considered essential. These include an analysis of policy documents and policy discourse, an 
analysis of legal precedents, or the comparative and longitudinal study of universal service obligations. Triangulation of the findings of such studies with an analysis of findings of public opinion research will lead to a richer picture of a society' considerations when defining certain services as essential services.

\section{Organisation and delivery of services - structural factors}

An analysis such as the one presented in this article is incomplete because it does not take structural factors into account. The analysis does not contain information on actual levels of service provision, recent changes in such provision, and the extent to which certain services are or are not used by the respondents. An international comparison at the macro-level may lead to limited results because of the very different nature of (public) service organisation and delivery in different countries. The examples are rife, and some have been referred to earlier in this article: some countries have extensive railway systems, while other may rely on coaches or have a higher dependency on cars. Even within countries, the organisation of transport networks may be of an entirely different nature in different regions. Some countries may have extensive gas supply networks, while this is less common in other countries.

Furthermore, this organisation and provision is subject to constant changes. The major change since this 1997 survey has been the penetration of internet connections, which has changed the nature of e.g. television, or banking services. Another example is the change in telephony, where mobile telephony is superseding fixed lines. These changes are visible in opinion data. We find a good example in Special Eurobarometer 260 (European Commission 2007). One of the questions in this survey asked respondents how important certain services were in their daily life. The findings for fixed telephony showed clear differences between countries. Respondents in most Central- and Eastern European countries (and in Finland, the mobile telephony Mecca) found fixed telephony considerably less important than those in Western European countries. An obvious explanation is the irrelevance of fixed telephony in these countries due to either the massive penetration of mobile phone, or the defective functioning of fixed telephony companies.

\section{Local explanations and comparative research}

The history, structure, and organisation of public services are quite different across European countries. Despite an increase in European regulation, the emergence of transnational public service providers, and a convergence in public sector reform rhetoric, public services across countries are remarkably diverse. This creates important challenges for safeguarding conceptual equivalence in comparative studies (van Deth 1998). For this reason, it is not only 
necessary to look for universal explanations for why citizens consider certain services as essential public services, but also for localised explanations. The reason why citizens in a certain country consider certain services as essential public services may for therefore have very little to do with universal principles, but with very local considerations. Analysing these national and local explanations may require a specific approach, which includes mapping path dependencies, critical junctures, the impact of specific crises and events and a sufficient degree of contextualisation overall.

\section{Data}

The data used in this analysis are quite old (1997). This needs not be a problem when searching for processes, elementary forms, or common foundations (Durkheim 1915), but may greatly reduce perceived policy relevance, or even the publishability of the findings. However, the data used here are unique. These questions have been asked only once in an internationally comparative survey, and disappeared from the Eurobarometer questionnaire afterwards. To our knowledge, they have not been used in any other analysis. As we have argued elsewhere, there still is a wealth of opinion data available to researchers, much of it underanalysed (Bouckaert, Van de Walle et al. 2005). The problem with using secondary data, however, is that data have not, generally, been collected for the purposes of the secondary analyst. Eurobarometer typically is a survey for policy-making purposes. Later surveys, with a focus on services of general interest, have therefore mainly focused on issues that are relevant to European policy makers, and not politically out of bound. Newer survey items therefore reflect current policy initiatives, or they reflect a desire to enter certain new policy areas in relation to services of general interest. Eurobarometer 65 in 2006 for instance deals with consumer complaints, consumer protection, contracts, switching providers, price information and affordability. An additional factor is the European Commission's view that the definition of what services are essential or 'of general interest' is not a matter to be decided at the European level (Commission of the European Communities 1996: 2). Determining whether a service is of general interest is considered to be a matter for national authorities under the subsidiarity principle (Van den Abeele 2005: 57). It may therefore be viewed as inappropriate for the Eurobarometer survey to include such questions.

Nevertheless, there may be other ways to study the perceptions of essentiality of public services by combining a range of national-level quantitative and qualitative studies, and extracting key findings. A number of studies are already available (Hope, Anderson et al. 2000; Ministère de l'Intérieur et de l'Aménagement du Territoire (France) 2005 (France); Van Roosbroek and Van de Walle 2006). 
Yet, despite this progress, there is a real need to stimulate the (transnational) collection of opinion data. Unlike other issues such as voting behaviour or attitudes towards the welfare states or taxation, there is remarkably little data and research on public attitudes towards public services. Where such data is available, it mainly reflects a consumerist approach through its focus on issues such as customer satisfaction or complaints handling. We know remarkably little about the values, dilemmas and choices underlying public attitudes towards public services delivery. Initiatives have been taken in some countries, as mentioned above, but these still mainly reflect local conditions and considerations.

\section{Towards new explanations}

While the findings in this article were mixed, they did suggest a number of explanations and avenues for further research. One factor that emerged from the research is experience. There were a number of instances where age has an impact on the assessment of certain services as essential services. Whereas younger people may consider certain public services as essential because they have always known a situation where such services are available, older respondents may have experienced periods without such services. This may especially be the case in rural areas, where services such as e.g. rubbish collection, or a connection to a water mains are relatively 'new' phenomena. Furthermore, many public services now considered as normal and essential are actually quite recent: access to TV channels, telephone, and more recently, internet are not exactly services that have always been available. Rather than studying public services in an absolute way ('what services are seen as essential'), one should look at factors explaining how essential services come to be seen as such, including how and when a service makes its transition from a luxury good to an essential one (Verhoest 2000: 605-6). Such a study will have to have as much attention for service characteristics, and issues of access and affordability, as for processes of political agenda-setting (see e.g. Prosser 2000; Héritier 2001).

A second, and related, factor is the impact of one's personal situation on attitudes towards public services, and the question of whether these services are essential. We may well assume that citizens employ an abstract conception of essential public services, but we cannot in fact exclude that the opinions measured in the survey are very personal and context-dependent opinions. That we have found such weak relations in the models (especially for what concerns the relation with political left-right orientations) may in fact be proof that these opinions are very pragmatic attitudes rather than highly-integrated, coherent, and abstract ones (Zaller 1996). A more in-depth analysis of attitudes held by a specific person in a specific context may actually do more to further our insight into the factors determining whether a service is seen as essential, than does the current survey-based approach. 
Finally, local or national circumstances are important. The debate about 'essentiality' is one that is mainly held at the national level. Attitudes towards public services and the values shaping these attitudes are an integral part of national administrative cultures, and national historical developments (Van de Walle 2008). This for instance means that looking for EUwide political left-right distinctions may ignore many of the subtleties of the national debates about the reform of public services. What's more, debates on public service reform or liberalisation, both in terms of content and in terms of the terminology used, are quite different across countries (Scott 2000).

\section{Reference List}

Bouckaert, G., S. Van de Walle, et al. (2005). "Potential for comparative public opinion research in public administration." International Review of Administrative Sciences 71(2): 229-240.

Clifton, J., F. Comin, et al. (2003). Privatisation in the European Union: Public enterprises and regulation. Dordrecht, Kluwer Academic Publishers.

Commission of the European Communities (1996). Communication from the Commission: Services of general interest in Europe. COM(96)443 final.

Commission of the European Communities (2001). Communication from the Commission: Services of general interest in Europe. 2001/C 17/04.

Cremer, H., F. Gasmi, et al. (2001). "Universal service: an economic perspective." $\underline{\text { Annals of }}$ Public and Cooperative Economics 72(1): 5-43.

De Bruijn, H. and W. Dicke (2006). "Strategies for safeguarding public values in liberalized utility sectors." Public administration 84(3): 717-735.

Durkheim, E. (1915). The elementary forms of the religious life. London, George Allen \& Unwin Ltd.

European Commission (2007). Special Eurobarometer 260, wave 65.3: Services of General Interest. Brussels, European Commission.

Freedland, M. (1998). Law, public services, and citizenship - new domains, new regimes? Public services and citizenship in European law: Public and labour law perspectives. M. Freedland and S. Sciarra. Oxford, Clarendon Press: 1-34.

Héritier, A. (2001). "Market integration and social cohesion: the politics of public services in European regulation." Journal of European Public Policy 8(5): 825-852.

Hope, S., S. Anderson, et al. (2000). The quality of services in rural Scotland. Edinburgh, Scottish Executive Central Research Unit.

INRA (1997). Eurobaromètre 47.0: L'Europe des consommateurs: les citoyens face a l'ouverture a la concurrence des monopoles de services publics. Brussels. 
Lehrer, D., J. Leschke, et al. (2007). "Negative results in social science." European Political Science(6): 51-68.

Loosveldt, G. and A. Carton (2002). "Utilitarian individualism and panel nonresponse." International Journal of Public Opinion Research 14: 428-438.

Ministère de l'Intérieur et de l'Aménagement du Territoire (France) (2005). Enquête nationale sur les Services publics en Milieu rural. Paris.

Prosser, T. (2000). "Public service law: privatization's unexpected offspring." Law and contemporary problems 63(4): 63-82.

Prosser, T. (2005). The limits of competition law: Markets and public services. Oxford, Oxford University Press.

Scott, C. (2000). "Services of general interest in EC law: Matching values to regulatory technique in the public and privatised sectors." European Law Journal 6(4): 310-325.

Van de Walle, S. (2006). "The impact of public service values on services of general interest reform debates." Public Management Review 8(2): 183-205.

Van de Walle, S. (2008). "What services are public? What aspects of performance are to be ranked? The case of 'services of general interest'." International Public Management Journal 11(3): 256-274.

Van de Walle, S., S. Van Roosbroek, et al. (2008). "Trust in the public sector: Is there any evidence for a long-term decline?" International Review of Administrative Sciences 74(1): 45-62.

Van den Abeele, E. (2005). "Les services d'intérêt général: État du débat européen." Courrier hebdomadaire du CRISP(1901-1902): 5-72.

van Deth, J. W. (1998). Comparative politics: the problem of equivalence. London, Routledge.

Van Roosbroek, S. and S. Van de Walle (2006). Werken aan de Overheid: De mening van de burger. Resultaten van de 4de WADO survey. Leuven, Instituut voor de Overheid.

Verhoest, P. (2000). "The myth of universal service: hermeneutic considerations and political recommendations." Media, culture and society 22: 595-610.

Zaller, J. (1996). The nature and origins of mass opinion. Cambridge, Cambridge University Press. 